\title{
STUDY OF THE EFFECT OF PLASMA ON THE EFFICIENCY OF NANOFIBER FILTERS
}

\author{
'David PAVLIŇÁK, ${ }^{1}$ Oleksandr GALMIZ, 'Jakub KELAR, 'Dušan KOVÁČIK, ${ }^{1}$ Mirko ČERNÁK, \\ ${ }^{1}$ Michal FLEISCHNER, ${ }^{1}$ Ali Jamaati KENARI, ${ }^{1}$ Pavel KOSíK, 'Jana SVOBODOVÁ, \\ 3Jakub ONDRÁČEK
}

\author{
${ }^{1}$ CEPLANT, Department of Physical Electronics, Masaryk University, Brno, Czech Republic, EU, \\ d.pavlinak@mail.muni.cz \\ ${ }^{2}$ NAFIGATE Corporation a.s., Prague, Czech Republic, EU \\ ${ }^{3}$ ICPF CAS, Department of Aerosol Chemistry and Physics, Prague, Czech Republic, EU
}

https://doi.org/10.37904/nanocon.2021.4335

\begin{abstract}
The aim of this work was to determine the effect of plasma on the substrate and on the nanofibers themselves. The PA6 nanofibrous material and the PP carrier were exposed to the effects of dielectric barrier plasma generated in air at atmospheric pressure. Changes in chemical composition, the effect on adhesions to the support substrate and especially the plasma effect on the filtration efficiency of the nanofiber material were studied.
\end{abstract}

Keywords: Nanofibers, plasma, adhesion, filtration efficiency

\section{INTRODUCTION}

Although nanofibers have been known to the scientific community for almost a hundred years, they have long remained on the brink of interest. It was not until the 1990s that there was a renaissance of nanofiber materials research. Thanks to their unique properties, high filtration efficiency, great free surface combined with good breathability, nanofiber materials are directly destined for filtration applications and come to the forefront of industrial interest.[1] At the beginning of the millennium, the last obstacle was solved - the efficient industrial production, and since then nothing has hindered mass commercial production. Thus today, it is common to encounter a nanofiber membrane as a component sportswear or separation filter in gas filters. [2] The recent COVID-19 pandemic, which globally started the mass production of cheap protective devices capable of trapping virus particles, also played a significant role in commercial spreading.[3] The nanofibers fabricated in a thin layer are a very fine material and cannot be easily handled. In practice, this is solved by their application on a carrier substrate, protecting them from damage. Unfortunately, the nanofiber membrane adheres very reluctantly to these substrates, so it must be properly fixed. In industrial production, this is usually solved by a lamination process, which means that the nanofibers are sophisticatedly glued to the substrate with an adhesive and covered with a protective mesh. However, this technique brings several complications and limitations to the useful properties of the resulting material. In addition, the lamination process significantly increases the cost of the production process.[4] Thus, for the production of disposable protective devices, such as respirators or protective suits, alternative possibilities of attaching nanofibers to the carrier are being sought. A relatively elegant method is the application of plasma to a support substrate, on which nanofibers are subsequently applied. If an atmospheric plasma source is used, this technology can be directly implemented in the in-line production process. It is also possible to apply plasma directly to the nanofiber network, which allows us to modify their chemical and physical properties. In this way, we obtain a functional, inexpensive nanomaterial that we can use for products with high added value. $[5,6]$ 
In this work, we focused on the use of dielectric barrier discharges in a coplanar arrangement. These plasma sources are able to generate low temperature energetic plasma over a relatively large area. Therefore, due to their construction, they are particularly suitable for processing textile materials. However, barrier discharges generated at atmospheric pressure also have their disadvantages. From a microscopic point of view, the energy in the plasma is focused into tiny channels called streamers. There is a risk that these energy channels can damage the material during treatment and create small holes inside it. In the case of minor damage to the carrier material, this is not yet a significant problem. However, if we wanted to modify the nanofibers themselves, the perforated nanofiber mesh would of course lose its unique filtering ability. In this work, we mainly focused on the preparation of nanomaterial for air filtration, and we will monitor the positive or adverse effect of plasma on filtration efficiency.

\section{EXPERIMENTAL PART}

\subsection{Materials and methods}

Nanofibers were prepared by electrospinning on a laboratory instrument Nanospider NS LAB 500 at spinning parameters: substrate feed rate $50 \mathrm{~mm} / \mathrm{min}$, distance between electrodes $140 \mathrm{~mm}$, applied voltage $55 \mathrm{kV}$. Spinning was performed on a $10 \mathrm{~cm}$ long rotating wire electrode. A $9 \%$ solution of polyamide 6 (PA6), (Ultramide B24, BASF) was used as spinning solution. The polymer granulate was dissolved in a mixture of acetic acid (glacial A.G., $99.8 \%$, PENTA s.r.o.) and formic acid (p.a. $99 \%$, PENTA s.r.o.) at room temperature. The support carrier material was a nonwoven polypropylene fabric (PP) weighing 17 and $80 \mathrm{~g} / \mathrm{m}^{2}$ (Pegatex S, PF Nonwovens Czech s.r.o.). Plasma treatment of materials was performed using a barrier plasma discharge (diffuse coplanar surface barrier discharge, DCSBD) with a coplanar arrangement of electrodes in a corundum dielectric. The operating frequency at $400 \mathrm{~W}$ of electrical input was approximately $15 \mathrm{kHz}$ at a sinusoidal applied voltage of $20 \mathrm{kV}$ (peak / peak). Due to the active cooling of the DCSBD with synthetic mineral oil, the surface temperature of the electrode did not exceed $80^{\circ} \mathrm{C}$ during the experiment. The treated materials were subsequently characterized by electron microscopy (SEM, MIRA 3, Tescan Brno s.r.o.), Infrared spectroscopy (ATR-FTIR, Bruker Vertex 80V, Bruker Optics) and photoelectron spectroscopy (XPS, AXIS Supra TM, Kratos). Adhesion tests were performed by the Loop test method, top-hung adhesive tape wound into a loop (TA.XTplusC, Stable Microsystem) with a load cell of $10 \mathrm{~N}$ and a peel speed of $5 \mathrm{~mm} / \mathrm{min}$. The size-resolved penetration of particles through the tested materials was measured by a filter testing system developed at ICP CAS (Czech Republic). Samples were tested for size-resolved filtration efficiency at a flow rate of $8.7 \mathrm{l} / \mathrm{min}$ (for a test sample with a diameter of $47 \mathrm{~mm}$ ) guaranteeing a forward speed of $10.6 \mathrm{~cm} / \mathrm{s}$. This frontal velocity corresponds to a flow rate of $95 \mathrm{l} / \mathrm{min}$ (with an average respirator surface of $150 \mathrm{~cm}^{2}$ ) - according to EN 149 standards.

\subsection{Influence of plasma treatment on the support substrate and increase of adhesive energy}

First of all, we studied the effect of plasma on the nonwoven PP fabric itself. The fabric was treated at $400 \mathrm{~W}$ for 10 and $60 \mathrm{~s}$ in the open air. Due to plasmachemical reactions, we expected an increase in the surface of the PP fabric of new polar functional groups (especially oxygen-rich groups such as $-\mathrm{OH}, \mathrm{C}=\mathrm{O}, \mathrm{COO}$ ). The presence of carbonyl and hydroxyl groups was confirmed by infrared spectroscopy, where we found small increase of vibrations in the region of 1630 and $1725 \mathrm{~cm}^{-1} .[7,8]$ These vibrations do not occur in the reference material. The intensity of these vibrations increases with the time of treatment. Similarly, we observed an increase in oxygen content using EDX and XPS spectroscopy. The values are given in Table 1. However, as the treatment time increases, so does the damage to the PP material itself. This damage is observed by SEM and manifests itself in the formation of small craters and bulges on the surface of the PP fiber (see Figure 1). For this reason, we chose the mean golden way for further analyzes, i.e. a treatment time of $10 \mathrm{~s}$. A more detailed C 1s XPS analysis showed the presence of carbonyl, hydroxyl and carboxyl groups after plasma treatment of the material and is consistent with the results from ATR-FTIR. We obtain similar results even after 
plasma processing the nanofibers themselves. Here, strong oxidative effects and morphological changes occur. The values are again given in Table 1.
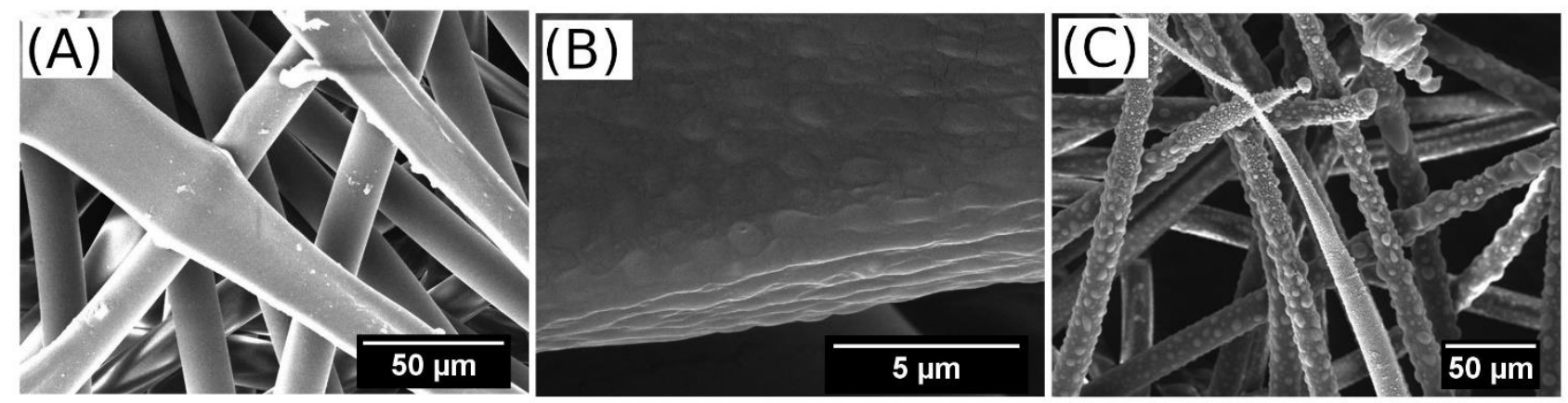

Figure 1 SEM Image of plasma treated PP substrate. (A) Reference PP - magnification $1500 x$; (B) PP plasma treatment $10 \mathrm{~s}$ - detail on fiber surface, magnification $50000 \mathrm{x}$; (C) PP plasma treatment $60 \mathrm{~s}-$ magnification $1000 x$

Table 1 Elemental composition of reference a plasma treated substrate and nanofibers measured by EDX and XPS spectroscopy

\begin{tabular}{|c|c|c|c|c|c|c|}
\hline \multirow{2}{*}{ Sample } & \multicolumn{3}{|c|}{ EDX (wt. \%) } & \multicolumn{3}{c|}{ XPS (at.\%) } \\
\cline { 2 - 7 } & C & N & O & C & N & O \\
\hline PP ref & 97.4 & 0.0 & 2.6 & 98.6 & 0.0 & 1.4 \\
\hline PP plasma 10s & 95.4 & 0.0 & 4.6 & 83.6 & 2.2 & 12.5 \\
\hline PA6 NF ref & 54.4 & 30.3 & 15.4 & 81.6 & 9.0 & 9.4 \\
\hline PA6 NF plasma 60 s & 52.4 & 28.3 & 19.3 & 77.6 & 9.2 & 13.2 \\
\hline
\end{tabular}

Of interest is the analysis of adhesion energy performed using a peel test. This test is normally performed using a rotating wheel to which the test sample is attached. A standardized adhesive tape is then adhered to the sample. The adhesive tape is then gradually mechanically torn off the sample. Figure 2 shows the result of the peel test. While the gradual tear-off of the untreated substrate is measurable, after the plasma treatment the adhesive force is too great, and the sample is damaged. The fibers of the PP substrate remain firmly attached directly to the surface of the tape, and in this way, we measure the cohesive forces inside the PP substrate itself (Figure 2). This method is also not suitable for determining the adhesion forces of nanofibers to a substrate. For this reason, we have developed a new type of method for determining the so-called loop test. The innovation of the method consists in omitting the rotating wheel, the samples are attached to a horizontal base, and the twisting of the standardized tape into a loop. The loop is then gradually lowered from above towards the sample, it is carefully attached to it and then it starts to tear away from it in the opposite movement. The device then tears the layers of the sample apart at a constant speed and at the same time measures the dependence of the adhesion force at a distance from the zero position of the instrument. Finally, it integrates this dependency to get the mechanical work done $W_{\text {adh. }}(\mathrm{N} \cdot \mathrm{mm})$. The adhesive energy is determined here using the following formula:

$$
E_{a d h .}=\frac{W_{a d h .}}{S} ;\left(J \cdot m^{-2}\right)
$$

where the $S$ is sample area (in our case square $2 \times 2 \mathrm{~cm}$ ). The method of determining the adhesive energy is inspired by the work of Rombaldoni et al.[9]

The resulting data for treated and untreated PP substrate are shown in Table 2. These results are of good order in correlation with our previous publication [5], where a different type of test was performed to determine 
the adhesive energy. Specifically, in this work the tearing test was proved of $180^{\circ}$ sample attachment in mechanical jaws. Because the results of both methods are mutually comparable, we can say that the determination of adhesion energy using the innovative Loop test is valid and applicable for the determination of adhesion energy. This method can determine both the increase in the adhesion of the treated substrate to the tape and the adhesion of the nanofibers to the support substrate.
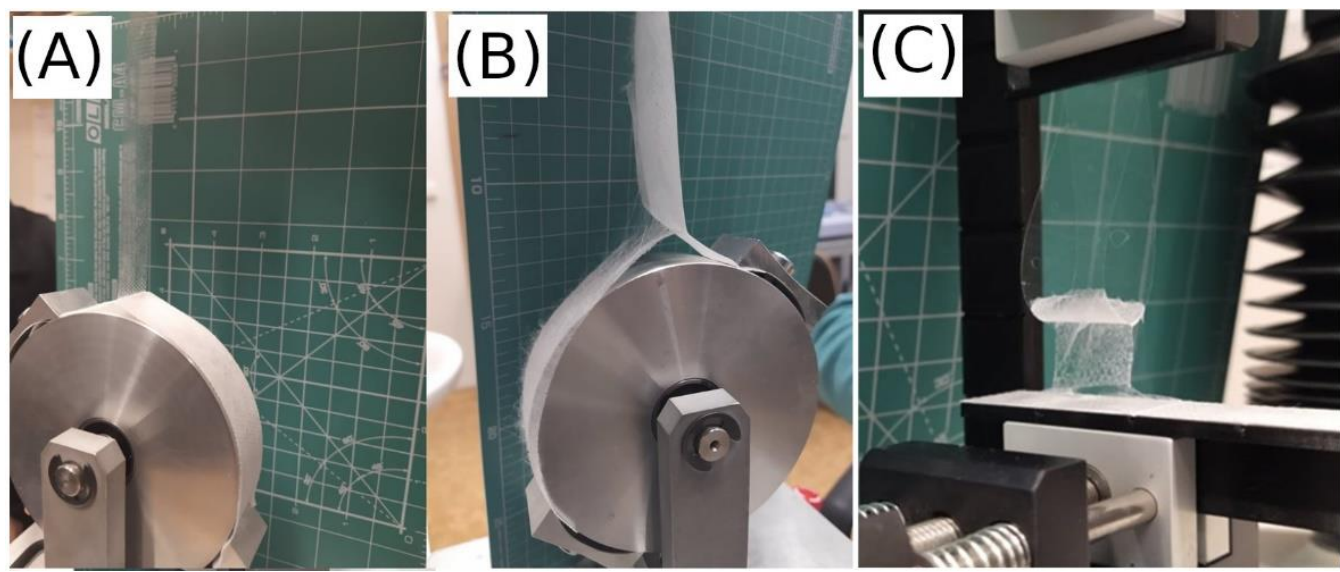

Figure 2 Peel test of plasma untreated (A) or treated $10 \mathrm{~s}$ PP substrate (B) and the Loop test of plasma treated $10 \mathrm{~s}$ PP substrate with deposited PA6 nanofibers (C)

Table 2 Determination of the average work required to tear nanofiber layer from the plasma treated, or untreated polypropylene substrate

\begin{tabular}{|l|c|c|c|}
\hline \multirow{2}{*}{ Sample } & \multicolumn{3}{c|}{ Loop test } \\
\cline { 2 - 4 } & $\mathbf{W}_{\text {adh. }}(\mathbf{N} \cdot \mathbf{m m})$ & Maximal force of adhesion $(\mathbf{m N})$ & $\mathbf{E}_{\text {adh. }}\left(\mathbf{J} \cdot \mathbf{m}^{-2}\right)$ \\
\hline NF PA6 on PP ref & 0.344 & 40 & 0.860 \\
\hline NF PA6 on plasma PP 10s & 0.959 & 154 & 2.397 \\
\hline
\end{tabular}

For creating high-quality adhesive joints (joint between textile fiber and other material) the material composition of the polymer fibers of the substrate itself has a great influence. The following sequence of the quality of the adhesive joint of basic types of textile fibers to various ones is investigated types of binders was experimental given for the most common textile materials [10].:

$$
\text { Viscose }>\text { polyamide }>\text { cotton }>\text { polyester }>\text { wool }>\text { polypropylene }
$$

Thus, the strongest adhesive joints are to viscose, the weakest for polypropylene substrate. This can be clearly seen also in the measured values of adhesion energy, when polyamide nanofibers have a very low adhesion to the polypropylene substrate. The adhesion force is influenced, among other things, by the morphology and chemical composition of the fibers surface. In practice, therefore, the fabrics are in industrial processes treated with chemical binders. [11,12] The effect of plasma on adhesion is very significant here. At almost all investigated values, we measured approximately threefold improvement in the adhesion of nanofibers to the substrate.

The exact causes of the increase in adhesion after exposure to plasma are not yet known. However, two probable hypotheses can be established from the above-mentioned analyses.

- $\quad$ Plasma causes unevenness on the surface of the substrate fibers - nanofibers are better mechanically captured to substrate 
- $\quad$ Oxidizing effects of plasma - adhesion energy could be increased due to the presence of reactive polar groups, which can stimulate the formation of new chemical bonds or physical interactions between materials (e.g. hydrogen bonds, electrostatic forces)

\subsection{Influence of plasma treated materials on filtration efficiency}

Table 3 shows the values of filtration efficiency depending on the treatment of the material in the plasma. As can be seen here, the PP substrate alone does not achieve filtration efficiency or the FFP1 category. In contrast, the nanofiber membrane achieves a filtration efficiency of $97 \%$ and therefore clearly meets the conditions for filtration category FPP1. from the measured values it is clear that the plasma does not have a negative effect on the filtration of the material and that both in the samples where only the carrier PP substrate was treated and sample where the nanofibers were also plasma treated.

Table 3 Filtration efficiency test

\begin{tabular}{|c|l|c|c|}
\hline \multicolumn{2}{|c|}{ Sample } & \multicolumn{2}{c|}{ Filtration efficiency test } \\
\cline { 3 - 4 } & & Filtration efficiency (\%) & Filtration class (EN 149) \\
\hline 1 & PP ref & $<7$ & $<$ FFP1 \\
\hline 2 & PP plasma (10 s) & $<7$ & $<$ FFP1 \\
\hline 3 & PP ref + PA6 NF & 97 & FFP3 \\
\hline 4 & PP plasma + PA6 NF & 97 & FFP3 \\
\hline 5 & PP ref + PA6 NF (plasma) & 91 & FFP3(2) \\
\hline 6 & PP plasma + PA6 NF (plasma) & 96 & FFP3 \\
\hline
\end{tabular}

During the analysis, we noticed that some samples where the carrier substrate was not treated with plasma abruptly decreased in filtration efficiency (see sample 5). This phenomenon appears to be random in this set of samples. We explain it that due to the poor adhesion of used materials. It is possible that between the nanofiber layer and substrate, the small air pockets can be formed through the manipulation with sample. It can cause that the testing gas can penetrate through the material without effective filtration which results in overall reduction in filtration efficiency up to limit of FFP2.

\section{CONCLUSION}

In conclusion, the application of plasma to the support substrate leads to improved adhesion properties to the nanofiber membrane. Plasma can also be applied to the nanofibers themselves, which can modify their morphology and their chemical composition. No negative effect of plasma on the filtration efficiency of the material was observed.

\section{ACKNOWLEDGEMENTS}

This work was supported by project In-line plasma technology for a large throughput manufacturing of advanced nanofiber-based filter fabrics (No. E01-14) funded by the European Light Industries Innovation and Technology initiative, which is funded by the European Union COSME Program for Competitiveness of Companies and Small and Medium Enterprises.

\section{REFERENCES}

[1] BARHOUM, A., RASOULI R., YOUSEFZADEH, M., RAHIER, H., BECHELANY, M. Nanofiber Technology: History and Developments. In: Barhoum A., Bechelany M., Makhlouf A. (eds) Handbook of Nanofibers, Cham, Springer, 2018 
[2] TEO, W-E, INAI, R., RAMAKRISHNA, S. Technological advances in electrospinning of nanofibers. Science and technology of advanced materials. [online]. 2011, vol.12, no. 1. Available from: https://doi.org/10.1088/1468$\underline{6996 / 12 / 1 / 013002}$

[3] ESSA, W. K., et al. Nanofiber-Based Face Masks and Respirators as COVID-19 Protection: A Review. Membranes. [online]. 2021, vol. 11, no. 4, p. 250. Available from: https://doi.org/10.3390/membranes11040250.

[4] YALCINKAYA, F.; HRUZA, J. Effect of laminating pressure on polymeric multilayer nanofibrous membranes for liquid filtration. Nanomaterials. [online]. 2018, vol. 8, no. 5, p. 272. Available from: https://doi.org/10.3390/nano8050272.

[5] PAVLIŇÁK, D. et al. Application of dielectric barrier plasma treatment in the nanofiber processing. Materials Today Communications. [online]. 2018, vol. 16, pp. 330-338. Available from: https://doi.org/10.1016/j.mtcomm.2018.07.010

[6] PAVLIŇÁK, D. et al. Functionalisation and pore size control of electrospun PA6 nanofibres using a microwave jet plasma. Polymer degradation and stability. [online]. 2014, vol. 108, pp. 48-55. Available from: https://doi.org/10.1016/j.polymdegradstab.2014.05.027

[7] KUPSTOV, A.H., ZHIZIN G.N. Handbook of Fourier transform Raman and infrared spectra of polymers. Amsterdam: Elsevier, 1998

[8] BARBES, L., C. RADULESCU, STIHI, C. ATR-FTIR spectrometry characterisation of polymeric materials. Romanian Reports in Physics. 2014, vol. 66, no. 3, pp. 765-777.

[9] ROMBALDONI F. et al. Adhesion enhancement of electrospun nanofiber mats to polypropylene nonwoven fabric by low-temperature oxygen plasma treatment. Surface and Coatings Technology. [online]. 2013, vol. 216, pp. 178-84. Available from: https://doi.org/10.1016/j.surfcoat.2012.11.056.

[10] KRCMA R. Teorie netkaných textilií. Liberec: Vysoká škola strojní a textilní, 1985.

[11] RUSSELL, S. J. Handbook of nonwovens. Cambridge: Woodhead publishing limited, 2006.

[12] SHERWOOD, N. Binders for nonwoven fabrics. Industrial \& Engineering Chemistry. [online]. 1959, vol. 51, no. 8, pp. 907-910. Available from: https://doi.org/10.1021/ie50596a026. 